\title{
Thin Cell Layer (TCL) Culture System for Herbal Biomass Production and Genetic Transformation of Bacopa monnieri L. Wettst.
}

\author{
LaMont Alexander Croom¹, Carissa L. Jackson², Brajesh Nanda Vaidya², \\ Prahlad Parajuli ${ }^{3}$, Nirmal Joshee ${ }^{2 *}$ \\ ${ }^{1}$ Alabama A \& M University, Huntsville, AL, USA \\ ${ }^{2}$ Agricultural Research Station, Fort Valley State University, Fort Valley, GA, USA \\ ${ }^{3}$ Wayne State University School of Medicine, Detroit, MI, USA \\ Email: "josheen@fvsu.edu
}

Received 18 May 2016; accepted 14 June 2016; published 17 June 2016

Copyright (C) 2016 by authors and Scientific Research Publishing Inc.

This work is licensed under the Creative Commons Attribution International License (CC BY). http://creativecommons.org/licenses/by/4.0/

(c) (i) Open Access

\section{Abstract}

Bacopa monnieri (L.) Wettst. (Scrophulariaceae) is a highly sought after medicinal plant with therapeutic properties as cognition enhancer as well as for other brain and body functions. Research was conducted to optimize a thin cell layer explant based micropropagation system to assist mass propagation. Thin cell layers (TCL) derived from leaf and internode segments were used as explants. Murashige and Skoog medium was used to formulate shoot induction, elongation, and rooting media. Shoot induction media were prepared by supplementing three concentrations $(0.1$, 1.0, and $10.0 \mu \mathrm{M}$ ) of four cytokinins 6-benzylaminopurine, 2-isopentenyl-adenine, 6-3-Hydroxybenzylaminopurine, and thidiazuron to study adventitious shoot bud induction response. An optimum shoot bud induction response was observed on MS medium supplemented with $10.0 \mu \mathrm{M}$ 6-benzylaminopurine for both leaf and stem transverse thin cell layer (tTCL) explants. The average number of shoot buds from leaf tTCL explants was 59, whereas, on an average, 33 shoot buds were regenerated from internode tTCL explants. Elongation of adventitious shoot buds was achieved best in a liquid medium using Liquid Lab Rocker ${ }^{\circledR}$ system. Elongated shoots recorded $100 \%$ rooting in MS medium supplemented with $5 \mu \mathrm{M}$ indole butyric acid. Bacopa micropropagation employing tTCL explants for initial shoot bud induction and using LLR $^{\circledR}$ boxes in subsequent elongation step can achieve cost effective way to regenerate high volume of plantlets and biomass required for herbal industry. Leaf and stem tTCL explants both were suitable for Agrobacterium tumefaciens (EHA105) mediated genetic transformation. Successful transformation was scored

\footnotetext{
${ }^{*}$ Corresponding author.
}

How to cite this paper: Croom, L.A., Jackson, C.L., Vaidya, B.N., Parajuli, P. and Joshee, N. (2016) Thin Cell Layer (TCL) Culture System for Herbal Biomass Production and Genetic Transformation of Bacopa monnieri L. Wettst. American Journal of Plant Sciences, 7, 1232-1245. http://dx.doi.org/10.4236/ajps.2016.78119 
within three days of co-cultivation with Agrobacterium suspension on the basis of Enhanced Green Fluorescent Protein (EGFP) expression as an early and non-destructible screening device. Transformation frequencies of $83 \%$ and $76 \%$ were accomplished for leaf and stem tTCL explants, respectively. Greenhouse grown Bacopa plants were analyzed as fresh and dry methanolic extracts for total polyphenol content (811.93 \pm 7.98 and $814 \pm 17.64 \mathrm{GAE}$ mg g-1) and the Trolox Equivalent Antioxidant Capacity values were $1918.25 \pm 173.12$ and $3163.14 \pm 403.25 \mu \mathrm{mol} / \mathrm{g}$, respectively.

\section{Keywords}

\section{Bacopa, Plant Tissue Culture, Total Polyphenols, Transformation, Transverse Thin Cell Layer}

\section{Introduction}

Bacopa monnieri (L.) Wettst. (Bacopa monniera, family Scrophulariaceae) is a well-documented herb in the traditional Ayurveda medical system attributed with medicinal properties improving cognition, such as memory retention, concentration, and learning [1]. Though Bacopa (locally known as Brahmi) is indigenous to India, it has been found in wild in countries as far away as Argentina [2]. In a few research communications, ecological status of this important herb in wild has been mentioned as endangered one [3]. In many countries, Bacopa species are also commercially sold as an aquatic plant for the aquarium. Flowers and fruits appear in summer and the entire plant is used for medicine. The bioactivity and medicinal properties have been assigned to the presence of alkaloids (nicotine, brahmine, herpestine), saponins (hersaponin, betulic acid, bacosides A, B, C and D) and other chemicals like stigmastanol, bsitosterol and stigmasterol [4]-[6]. Clinical studies have further evaluated the nootropic potential of Bacopa monnieri and confirmed its cognition-enhancing effects, attributing the effects to bioactive compounds collectively known as "bacosides" [7]. Bacosides are a type of saponin triterpene, and the bioactive compounds Bacosides A and B aid in the repair of damaged neurons by enhancing kinase activity, neuronal synthesis, restoration of synaptic activity, and ultimately, nerve impulse transmission [8].

Though there are a few reports on the micropropagation of Bacopa monnieri [9] [12]-[14], a thorough study to maximize plant production with minimum tissue requirement for initial explant is lacking. To ensure large scale commercial production of biomass for herbal industry, it would be pertinent to bring down the cost of production. Significant cost reduction can be achieved with liquid culture system [10] [11].

Further, most of the regeneration studies conducted earlier on Bacopa are restricted to the use of cytokinins such as kinetin, BAP [12] [13] and TDZ [14]-[18]. Recent regeneration studies in Spathiphyllum floribundum Schott cv. Petite and Hisbiscus sabdariffa L. a compound with cytokinin like activity known as meta-Topolin shows promising results [19] [20]. Other cytokinins like 2-iP can also induce adventitious bud induction in Bacopa either using individually or in combination with an auxin [21]. Thin cell layer (TCL) culture system is one of the options to ensure minimal use of tissue as an explant. By definition, thin cell layer culture is the use of small explants (width: $0.1 \mathrm{~mm}$ to $1 \mathrm{~mm}$ and length: $5-10 \mathrm{~mm}$ ) [22]. Depending on the incision made, an explant can either be longitudinal or transverse thin cell layer (l or tTCL). As a result of their reduced size, more cells within a thin cell layer explant are "morphogenically responsive" due to their close contact with the growth medium [22]. The effects of cytokinins, auxins, photoperiod, on successful regeneration and biolistic or bacterial-mediated transformation have been reported in species such as Nicotiana tabacum, Lilium longiflorum, Lycopersicon esculentum, Dendranthema x grandiflora, Eclipta alba, Orchids and various species of Rose thin cell layer cultures [23]-[28]. There are no reported studies that evaluate the effects of cytokinins on thin cell layer (TCL) explants of B. monnieri for improved and efficient plant production. Recent advances in metabolic engineering have made it possible to increase the concentration of desired compounds as well as introduce novel biosynthetic pathways leading into the production of novel bioactive compounds [29] [30]. To improve metabolic engineering capabilities, it is important to have an efficient in vitro multiplication protocol in place. Genetic transformation studies that have been carried out in Bacopa genus so far have been summarized in Table 1 . This study seeks to optimize adventitious shoot bud induction to facilitate herbal biomass production, role of liquid culture in shoot elongation, rooting and genetic transformation potential of tTCL explants. 
Table 1. A review of genetic transformation research on Bacopa monnieri.

\begin{tabular}{|c|c|c|c|c|c|c|c|c|c|c|c|c|}
\hline \multirow{2}{*}{ Plant } & \multicolumn{2}{|c|}{$\begin{array}{l}\text { Transformation } \\
\text { method }\end{array}$} & \multirow[t]{2}{*}{ Plasmid } & \multicolumn{4}{|c|}{ Reporter gene } & \multirow[t]{2}{*}{$\begin{array}{l}\text { Selection } \\
\text { agent }\end{array}$} & \multicolumn{3}{|c|}{ Molecular identification } & \multirow{2}{*}{ - Ref. \# } \\
\hline & $\begin{array}{c}\text { A. } \\
\text { rhizogenes }\end{array}$ & $\begin{array}{c}\text { A. } \\
\text { tumefaciens }\end{array}$ & & GUS & nptII & hpt & hptII & & PCR & RT-PCR & $\begin{array}{l}\text { Southern } \\
\text { blotting }\end{array}$ & \\
\hline Bacopa monnieri & $\begin{array}{l}\text { LBA9402 } \\
\text { and A4 }\end{array}$ & & $\begin{array}{l}\text { pRi1855 and } \\
\text { pRiA4 }\end{array}$ & & & & & $\begin{array}{l}\text { Kanamycin } \\
\text { Rifampicin }\end{array}$ & • & - & & {$[44]$} \\
\hline $\begin{array}{l}\text { Bacopa monnieri } \\
\text { (L.) Wettst. }\end{array}$ & & LBA4404 & pBI121 & $\cdot$ & $\cdot$ & & & Kanamycin & • & • & & [45] \\
\hline $\begin{array}{l}\text { Bacopa monnieri } \\
\text { (L.) Pennell }\end{array}$ & & $\begin{array}{l}\text { LBA4404, } \\
\text { EHA105, } \\
\text { GV } 3101\end{array}$ & pCAMBIA2301 & - & • & & & $\begin{array}{l}\text { Kanamycin } \\
\text { Cefotaxime }\end{array}$ & - & & & [46] \\
\hline $\begin{array}{l}\text { Bacopa monniera } \\
\text { (L.) Wettst. }\end{array}$ & & GV2260 & pCAMBIA1301 & • & & & $\cdot$ & $\begin{array}{c}\text { Hygromycin } \\
\text { B }\end{array}$ & • & & • & [47] \\
\hline $\begin{array}{l}\text { Bacopa monnieri } \\
\text { (L.) }\end{array}$ & & EHA105 & pCAMBIA1301 & • & & - & & Hygromycin & - & & & [43] \\
\hline $\begin{array}{l}\text { Bacopa monnieri } \\
\text { (L.) Wettst. }\end{array}$ & & EHA105 & pBE2113 & $\cdot$ & • & & & Kanamycin & • & • & & [42] \\
\hline
\end{tabular}

\section{Materials and Methods}

\subsection{Transverse Thin Cell Layer Culture (tTCL) of B. monnieri}

\subsubsection{Preparation of Plants for Mother Stock}

Bacopa plants that were growing in the greenhouse were sterilized using a procedure optimized in our lab [16]. After sterilization nodal explants were established as in vitro cultures on Murashige and Skoog (MS) medium [31] with vitamins (PhytoTechnology Lab, KS, USA). These plants were allowed to grow for four weeks in test tubes with $15 \mathrm{~mL}$ culture medium under $16 \mathrm{~h}$ photoperiod at $24^{\circ} \mathrm{C} \pm 2{ }^{\circ} \mathrm{C}$, and then used for harvesting explants for all the experiments.

\subsubsection{Explant Selection}

Plant materials were harvested from the aseptic mother stock maintained on MS basal medium. The leaf and stem tTCL explants were aseptically excised using surgical blade No. 11 (Feather, Osaka, Japan) from axenic mother cultures of B. monnieri, to achieve the desired sizes. Using fully expanded in vitro leaf and internode stem tissues, tTCL explants were prepared. The average initial tTCL leaf explant dimensions were less than 3 $\mathrm{mm}$ in length and $1 \mathrm{~mm}$ in width and the stem explant dimensions were about $1.5-2.0 \mathrm{~mm}$ in diameter and 1.0 $1.5 \mathrm{~mm}$ in thickness.

\subsubsection{Media and Culture Conditions for Multiple Adventitious Shoot Induction}

MS medium with vitamins was fortified with $3 \%(\mathrm{w} / \mathrm{v})$ sucrose and $0.8 \%(\mathrm{w} / \mathrm{v})$ agar (Caisson Labs, UT, USA). This medium was used to observe the rate of multiple shoot induction from using leaf and internode tTCLs explant by incorporating three concentrations of four cytokinins or compounds with cytokinins like activity.

Three concentrations $0.1 \mu \mathrm{M}, 1.0 \mu \mathrm{M}$, and $10 \mu \mathrm{M}$, each of four cytokinins viz. 6-benzylaminopurine (BAP) (PhytoTechnology Lab, KS, USA), 2-isopentenyl-adenine (2-iP) (Sigma Aldrich, MO, USA), meta-Topolin ( $m$-Topolin) (PhytoTechnology Lab, KS, USA), and Thidiazuron (TDZ) (Sigma Aldrich, MO, USA), and a control containing no plant growth regulators, were incorporated into MS medium. The $\mathrm{pH}$ was adjusted to 5.8 before autoclaving at $121^{\circ} \mathrm{C}$ for 15 minutes. The sterilized media was dispensed into sterile plastic Petri dishes $\left(100 \mathrm{~mm} \times 15 \mathrm{~mm}\right.$; Fisher Scientific, MA, USA) and allowed to solidify in the sterile condition at $25^{\circ} \mathrm{C}$. Five leaf and five stem tTCL explants were inoculated in each petri dish and three petri dishes for each treatment were inoculated.

\subsection{Elongation, Rooting, and Acclimatization in Greenhouse}

After 14 days of incubation in the initial shoot induction medium with various cytokinins, explants with adventitious shoot buds were transferred to the elongation medium to induce further shoot growth. Liquid MS basal 
medium with $1 \%$ sucrose was used as elongation medium and $40 \mathrm{~mL}$ of it was dispensed in each LLR $^{\circledR}$ box. Five tTCL explants (either leaf or stem) with multiple shoot buds were transferred to each $\operatorname{LLR}^{\circledR}$ box. These cultures were incubated at $25^{\circ} \mathrm{C} \pm 2{ }^{\circ} \mathrm{C}$ for two weeks. Once healthy root system was visible, plants were removed from the $\operatorname{LLR}^{\circledR}$ boxes and washed under tap water to remove medium and sucrose. Plants with clean roots were transferred to plastic pots containing potting mixture (Promix BX, Premier Tech Horticulture, PA, USA) and placed under the mist chamber for acclimatization. Plants were then removed from the mist chamber after a week and maintained in the greenhouse to monitor further growth.

\subsection{Scanning Electron Microscopy}

Samples were processed through fixation, dehydration, critical point drying and sputter coating prior to analyzing adventitious shoot bud induction under scanning electron microscope (S 3400N II, Hitachi High Technologies America Inc., CA, USA). The protocol followed has been optimized in our lab and published earlier [32]. The gold coating was at $50 \AA$. Coating was carried out for $60 \mathrm{~s}$ under a vacuum pressure of 0.05 torr using 30 $\mathrm{mA}$ current. Digital images were collected at various magnifications running beam at $10 \mathrm{kV}$ and keeping specimen stub at $4.4 \mathrm{~mm}$ distance. All scanning works were conducted at the Agricultural Research Station, Fort Valley State University, Fort Valley, Georgia, USA.

\subsection{Agrobacterium tumefaciens-Mediated Genetic Transformation of tTCL Explants}

The standard protocol for Agrobacterium tumefaciens-mediated transformation of B. monnieri leaf and stem tTCL cultures was optimized testing the following parameters - choice of explants, bacterial suspension preparation, acetosyringone concentration added to the bacterial culture prior to co-cultivation, and co-cultivation time. Agrobacterium tumefaciens EHA 105 competent cells previously prepared and stored at $-80^{\circ} \mathrm{C}$ were transformed with plasmid (pq35SGR, 14469 bp; kindly provided by Dr. Dennis J Gray, University of Florida). This plasmid contains EGFP, GUS/NPTII fusion reporter genes and the plasmid harboring bacteria was cultured in 2 YT plates with $20 \mathrm{mg} / \mathrm{L}$ rifampicin (Sigma Aldrich, MO, USA), and $50 \mathrm{mg} / \mathrm{L}$ kanamycin (Sigma Aldrich, MO, USA) antibiotics. The plates were then incubated in the dark at $28^{\circ} \mathrm{C}$ for $48-72 \mathrm{~h}$. Once the clean, isolated, and single conspicuous colonies were visible, they were picked to initiate new cultures. A single colony was selected to prepare bacterial culture for co-cultivation.

\subsubsection{Co-Cultivation of tTCL Explants}

Agrobacterium culture was placed in incubator $\left(27^{\circ} \mathrm{C}\right)$ at $160 \mathrm{RPM}$ for further growth. After $24 \mathrm{~h}, 3 \mathrm{~mL}$ of Agrobacterium culture was mixed with $23 \mathrm{~mL}$ of MG/L medium with $20 \mathrm{mg} / \mathrm{L}$ rifampicin and $50 \mathrm{mg} / \mathrm{L}$ Kanamycin [33] in $50 \mathrm{~mL}$ falcon tubes (BD, NJ, USA), and placed back in the incubator (Amerex Instruments, Inc., CA, USA) for growth. Optical density (OD) of Agrobacterium culture was measured at $600 \mathrm{~nm}$ using spectrophotometer (Nanodrop 2000c; Thermo Scientific, MA, USA) after $24 \mathrm{~h}$. Once the bacterial culture $\mathrm{OD}_{600}$ reaches between 0.4 and $0.6,100 \mu \mathrm{M}$ of acetosyringone (Phyto Technology Laboratories, KS, USA) was added to the bacterial culture and was further incubated for $2 \mathrm{~h}$. The shoot and leaf tTCLs were transferred to sterile petri dish (Fisher Scientific, MA, USA) with $10 \mathrm{~mL}$ of Agrobacterium culture suspension for $25 \mathrm{~min}$. Explants were placed in the bacterial suspension for $25 \mathrm{~min}$ and the suspension was swirled occasionally to provide explant cut surface for attachment of Agrobacterium. After 25 min of co-cultivation, explants were removed from the bacterial suspension and excess bacterial solution was removed by blotting explants on a sterile filter paper. The tTCL explants were placed in petri dish containing sterile filter paper and $3 \mathrm{~mL}$ of liquid MS medium was used to keep explants moist and maintain high humidity required for agro-infection. The petri dishes were wrapped with Parafilm ${ }^{\circledR}$ (American National Can Co., CT, USA), placed in incubator $\left(27^{\circ} \mathrm{C}\right)$ for $48 \mathrm{~h}$. After $48 \mathrm{~h}$, the explants were blotted to remove excess Agrobacterium on sterile tissue paper and placed in washing solution containing liquid MS medium supplemented with $1 \mu \mathrm{M}$ BAP, $250 \mathrm{mg} / \mathrm{L}$ cefotaxime (Caisson Lab, UT, USA) and $250 \mathrm{mg} / \mathrm{L}$ carbenicillin (Caisson Lab, UT, USA). After washing explants for three hours in washing solution, cultures were transferred to semi-solid MS medium with $2.5 \mu \mathrm{M}$ BAP, $250 \mathrm{mg} / \mathrm{L}$ cefotaxime (Caisson Lab, UT, USA) and $250 \mathrm{mg} / \mathrm{L}$ carbenicillin. The explants were observed daily under UV light for EGFP expression (Olympus SZX12 with DP 71 camera; Olympus, PA, USA) in developing adventitious shoots, other organs and tissues. Transformation of 25 leaf and stem tTCL explants was repeated three times to score transformation frequency. 


\subsubsection{Selection of Putative Transformants}

The transformed stem and leaf tTCL explants were selected on MS based shoot induction medium containing 30 $\mathrm{mg} / \mathrm{L}$ kanamycin. Cultures were incubated under $16 \mathrm{~h}$ photoperiod at $25^{\circ} \mathrm{C}$. After 30 days on the selection medium, only the kanamycin resistant tTCL leaf and stem explants survived that developed into shoots when transferred to fresh optimized regeneration medium (MS + 3\% sucrose, $10 \mu \mathrm{M}$ BAP, $250 \mathrm{mg} / \mathrm{L}$ carbenicillin, $250 \mathrm{mg} / \mathrm{L}$ cefotaxime, and $30 \mathrm{mg} / \mathrm{L}$ kanamycin). Developing adventitious shoots were regularly examined for EGFP expression and once elongating shoots expressed GFP uniformly, they were also evaluated utilizing the histochemical GUS assay [34] employing $\beta$-Glucuronidase reporter gene staining Kit (Sigma-Aldrich, MO, USA). Chlorophyll was removed from the putative transgenic tissue by passing it through 2 - 3 changes of $70 \%$ ethanol and the blue stain developed was photographed as outlined by the manufacturer.

\subsubsection{Molecular Characterization of Putative Transgenic Plants}

\section{Reverse Transcription-Polymerase Chain Reaction (RT-PCR) Analysis}

Total RNA from non-transgenic and transgenic Васора plants were extracted from the leaves using a modified TRIzol ${ }^{\circledR}$ reagent (Ambion/Life Technologies ${ }^{\mathrm{TM}}$, NY, USA) method. RNA quantification was done using a NanoDrop 2000c Spectrophotometer (Thermo Scientific, MA, USA). RT-PCR was performed with 600 ng of RNA using a One Taq ${ }^{\circledR}$ One-Step RT-PCR Kit (New England Biolabs Inc., MA, USA). Reverse transcription was conducted in PCR tubes at $48^{\circ} \mathrm{C}$ for $30 \mathrm{~min}$, followed by initial denaturation at $94^{\circ} \mathrm{C}$ for one min, and 40 cycles of denaturation at $94^{\circ} \mathrm{C}$ for $15 \mathrm{~s}$, annealing at $65^{\circ} \mathrm{C}$ for $30 \mathrm{~s}$, and extension at $68^{\circ} \mathrm{C}$ for $1 \mathrm{~min}$. Final extension was carried out at $68^{\circ} \mathrm{C}$ for $5 \mathrm{~min}$. The negative control consisted of the same reaction samples described above except for the absence of the One Taq ${ }^{\circledR}$ One-Step enzyme. Equal amount (400 ng) of control and experimental cDNAs were used as template for performing PCR. A forward primer EG-51 (50-ATG GTGAGCAAGGGCGAGGAGCTGT-30) and a reverse primer EG-32 (50-CTTGTACAGCTCGTCCATGCCG AGA-30) were used to amplify the egfpgene. The RT-PCR products were analyzed using $1.0 \%(\mathrm{w} / \mathrm{v})$ agarose stained with GelRed ${ }^{\mathrm{TM}}$ (Biotium, CA, USA).

\subsection{Antioxidant Capacity Measurement of B. monnieri Leaves}

Extracts Preparation, Total Polyphenol (TPP) Content Measurement and TROLOX Equivalent Antioxidant Capacity (TEAC) Assay

Tissue processing and extract preparation was carried out as described earlier [35]. In brief, liquid nitrogen was used to grind $2 \mathrm{~g}$ of fresh and dried whole plant samples of B. monnieri in a chilled mortar and pestle. The ground tissues were extracted overnight $(14 \mathrm{~h})$ in dark at $25^{\circ} \mathrm{C}$ using $50 \mathrm{~mL}$ methanol (Burdick and Jackson, MI, USA) using orbital shaker (Benchmark Mini Incushaker, NJ, USA) at 200 RPM. Extracts were centrifuged at $8000 \times \mathrm{g}$ (Eppendorf centrifuge $5810 \mathrm{R}$; NY, USA) for $15 \mathrm{~min}$ and supernatant were collected in a $50 \mathrm{~mL}$ clean tubes (Corning, NY, USA). The pellets in the tubes were further extracted two more times for 30 min each in 50 $\mathrm{mL}$ methanol. All extracted fractions were combined and passed through a $0.2 \mu \mathrm{m}$ nylon filter (Nalgene, NY, USA) before storage and downstream processing. The TPP experiments were carried out in quadruplicate and the mean TPP values for both fresh and dried plant extract of B. monnieri were quantified as $\mu \mathrm{g} / \mathrm{g}$ Gallic Acid Equivalents (GAE).

Total polyphenol content (TPP) was determined by the Folin-Ciocalteu reagent method [36]; and antioxidant capacity measurement was determined using TROLOX Equivalent Antioxidant Capacity (TEAC) assay [37] with modification [38]. Rosemary (Rosmarinus officinalis) leaf extracts were used as the internal standard to compare antioxidant capacity. The absorption values were recorded at $765 \mathrm{~nm}$ with Nanodrop 2000c spectrophotometer (Thermo Scientific, MA, USA) for both assays after standard curves were generated.

\subsection{Statistical Analysis}

The shoot induction experiments were carried out in triplicate for each treatment. A total of 15 explants from each type (leaf and stem tTCL) were used to score data. Once the optimum medium was identified, the same preparations were carried out in triplicate to record the shoot induction of the tTCL cultures. The experiments were set up in completely randomized design and repeated three times. A one-way Analysis of Variance (ANOVA) between subjects was conducted to compare the effect of type of cytokinin and concentration on shoot 
induction for B. monnieri's tTCL leaf and stem explants with results at $P<0.05$ level. The significant means were separated using Tukey's post-hoc mean separation test. All data are presented as means \pm SE for each sample.

\section{Results}

\subsection{Organogenesis Using tTCL of B. monnieri}

\section{Adventitious Shoot Organogenesis and Elongation}

A preliminary investigation was carried out to test the suitability of MS and Gamborg's B5 medium [39] for tTCL based micropropagation. Employing visual observations like explant establishment, response time, explant necrosis and browning, and number of shoot buds generated during first four weeks of culture, MS medium proved more suitable. Subsequent experiment on adventitious shoot bud induction using tTCL explants were carried out by supplementing MS based medium with three concentrations of four cytokinins as outlined above. Another preliminary study supported by qualitative observations revealed that the inclusion of auxin NAA even at $0.1 \mu \mathrm{M}$ resulted in the development of multiple roots (data not presented). As our interest is multiple shoot induction, auxin NAA was omitted from shoot induction media treatments. Morphogenic response of leaf and stem tTCL explants has been shown in the Figure 1. In this experiment, MS supplemented with $10 \mu \mathrm{M}$ BAP resulted
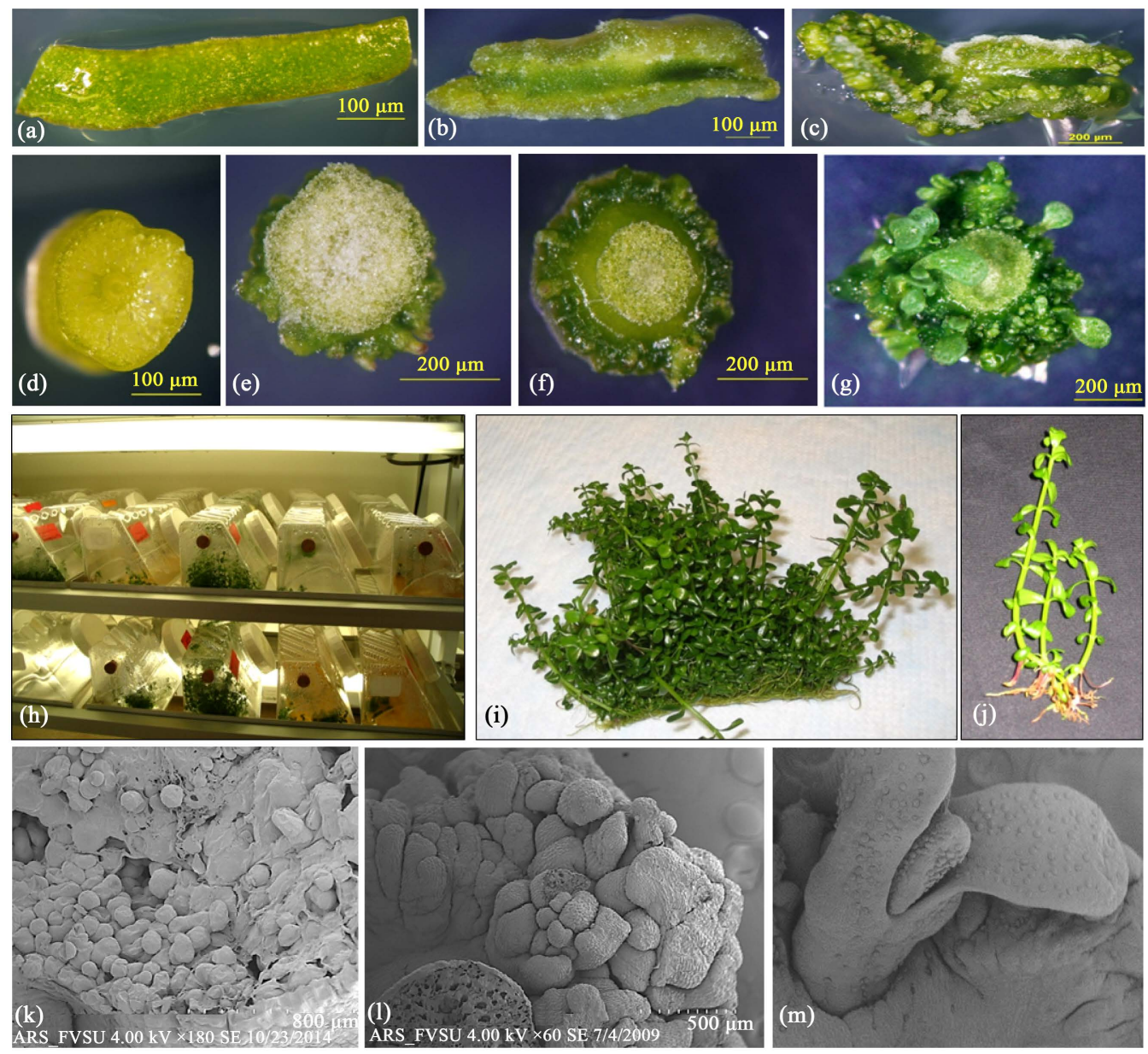

Figure 1. Various stages in adventitious shoot bud induction of B. monnieri leaf tTCL. (a) tTCL at day 1; (b) tTCL at 10 day; (c) tTCL at 14 day. Various stages in adventitious shoot bud induction of B. monnieri stem tTCL. (d) tTCL at day 1; (e) tTCL at 10 day; (f) tTCL at 14 day; (g) tTCL at 21 day. Various stages in elongation and rooting of B. monnieri leaf and stem tTCL in LLR system. (h) Utilization of LLR system to mass propagate B. monnieri after shoot bud induction in liquid MS medium; (i) A vigorously growing clump of elongated shoots of B. monnieri leaf tTCL after transferred to LLR boxes; (j) Rooted shoots of B. monnieri plantlet ready to be transferred to potting medium; (k)-(l) Sequence of callus induction and adventitious shoot production on the stem tTCL of Bacopa; (m) A single adventitious shoot in detail. 
in the best response for adventitious shoot bud induction from leaf (59) as well as stem (33) tTCL explants (Figure 2). Among all the cytokinins used, 2-iP exhibited poorest response as at $0.1 \mu \mathrm{M}$ level no shoot bud induction was visible, as did the control treatment with no cytokinin (Figure 2). Explants were transferred to liquid MS basal mediums with $1 \%$ sucrose after 14 day exposure on shoot induction medium to ensure elongation of shoots (Figure 1(c) and Figure 1(g)). Elongated shoots were removed from the elongation medium after three weeks and were photographed to record shoot length and root induction (Figure 1(i)). BAP treatment at $10 \mu \mathrm{M}$ scored 879 shoots in total from 15 tTCL explantsafter a 14 day incubation producing highest shoot count for leaf tTCL. Other treatments like $0.1 \mu \mathrm{M}$ of m-Topolin only had 24 shoots and $0.1 \mu \mathrm{M}$ of 2-iP did not produce any shoots at all. The average numbers of shoots harvested from the most favorable treatment for leaf tTCL was 59 shoots per explant (Figure 1(i) and Figure 2). Overall, leaf tTCL explants produced more adventitious shoot buds when compared to stem tTCLs.

To carry out liquid medium assisted elongation, culture assembly used is shown in the Figure 1(h). Culture boxes receive light from top and bottom both and are gently rocked (10 times/minute). Bacopa shoots elongated rapidly and a clump of elongated shoot generating from tTCL explant looks like Figure 1(i). It is interesting to note that shoots elongated rapidly and some of the clumps that received lower levels of cytokinins concentration rooted as well (Figure 1(j)). Another notable feature of elongation phase was no incidence of hyperhydricity in Bacopa shoots.

\subsection{Root Induction and Elongation}

Two to three cm long Bacopa monnieri shoots resulted in the establishment of well-developed root systems when transferred to semi-solid MS basal medium supplemented with $1 \%$ sucrose and $0.7 \%$ agar. Majority of shoots rooted in this medium. Addition of $5 \mu \mathrm{M}$ Indole-3-butyric acid (IBA) (PhytoTechnology Lab, KS, USA) into MS basal medium, resulted in higher number of shoots striking roots within a shorter incubation time (7 - 10 days) [16].

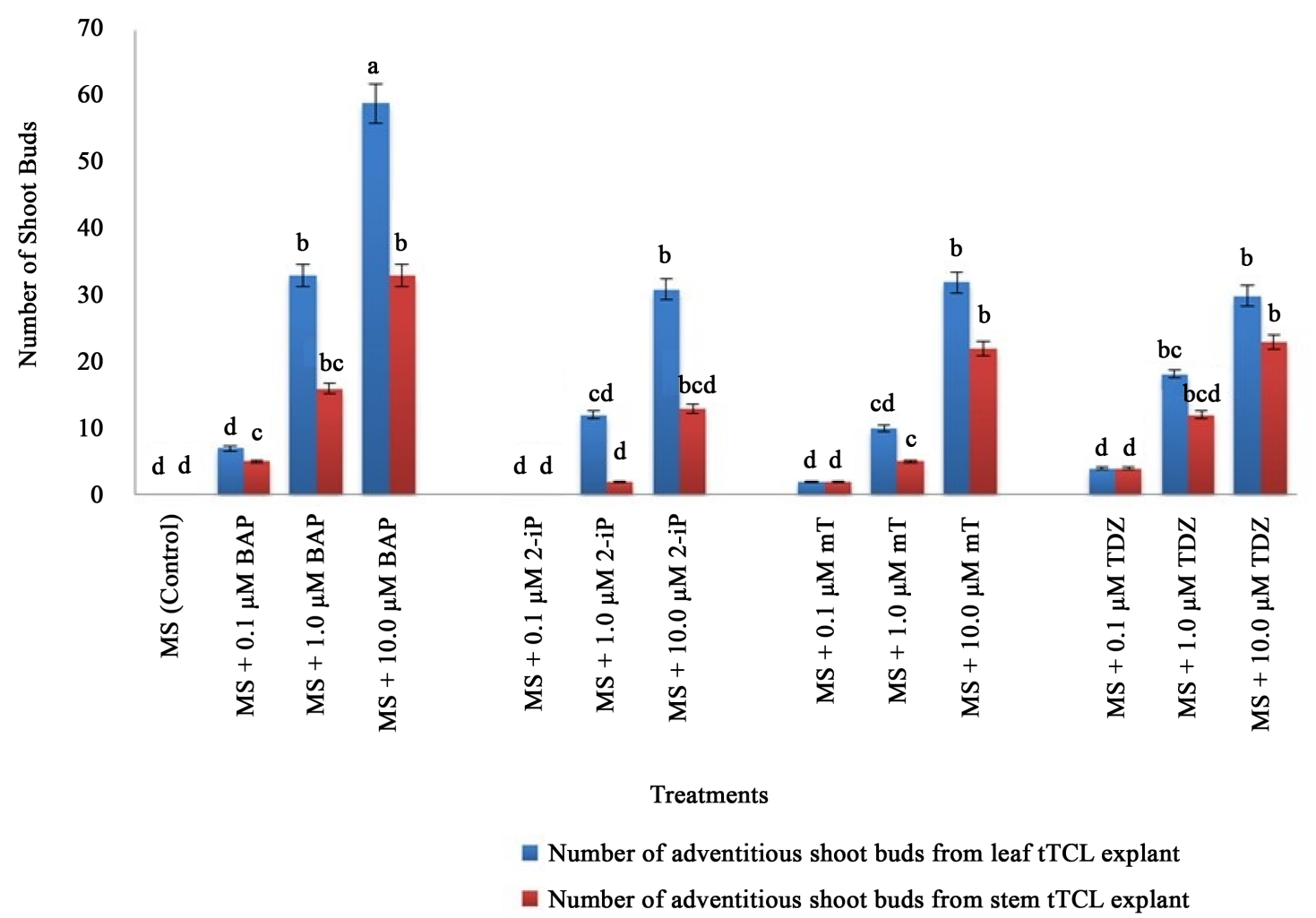

Figure 2. Adventitious shoot bud induction on leaf and stem tTCL explants of B. monnieri in response to various cytokinin treatments. Each mean and \pm SE is based on three replicates of fifteen explants. Means having different superscript alphabets are significantly different from each other $(p<0.05)$. 


\subsection{Agrobacterium tumefaciens-Mediated Genetic Transformation of tTCL Explants}

The latest reported studies on Agrobacterium tumefaciens-mediated transformation report efficient, rapid, and simple protocols with the highest transformation frequency being reported at $68.8 \%$ [40]-[47]. The reporter genes $\beta$-glucuronidase and neomycin phosphotransferase are the two genes that have been used in prior research [42] [43]. There are no reports that evaluate the Agrobacterium tumefaciens-mediated transformation of tTCL $B$. monnieri. The EGFP protein expression proved to be very effective in selecting transiently expressed tTCL leaf and stem explants, to be moved to selection medium and later elongated (Figures 3(a)-(c)). After three independent studies for both the tTCL leaf and tTCL stem explants a transformation frequency of $83 \%$ and $76 \%$ was accomplished respectively (data not presented).

\subsubsection{GUS Analysis of Transgenic Cultures and Plants}

Transient GUS expression was determined from explants five days after co-cultivation, whereas stable GUS expression in transgenic cultures and plants was recorded after three months of co-cultivation using manufacturer's instructions.

\subsubsection{RT-PCR Analysis of GFP Transcript}

Using the primers outlined in the Materials and Methods section, an approximately $774 \mathrm{bp}$, single band was amplified (Figure 4). This corresponds to PCR generated fragment using the same primers on genomic DNA isolated from putative transgenic plant (data not shown).

\subsection{Antioxidant Studies of $B$. monnieri Leaves}

The Folin-Ciocalteu reagent method and TROLOX Equivalent Antioxidant Capacity (TEAC) assay was utilized to analyze the total polyphenol content (TPP) and antioxidant capacity of B. monnieri herb. The Gallic Acid Equivalent (GAE) values were $811.93 \pm 7.98 \mathrm{mg} / \mathrm{g}$ and $814 \pm 17.64 \mathrm{mg} / \mathrm{g}$, for the fresh and dried methanolic extracts of B. monnieri providing a measure of total flavonoids. The TEAC values $1918 \pm 173.12 \mu \mathrm{mol} / \mathrm{g}$ and $3163.14 \pm 403.247 \mu \mathrm{mol} / \mathrm{g}$ (Table 2), for the fresh and dried plant extracts of B. monnieri indicate this plant to possess high antioxidant capacity.
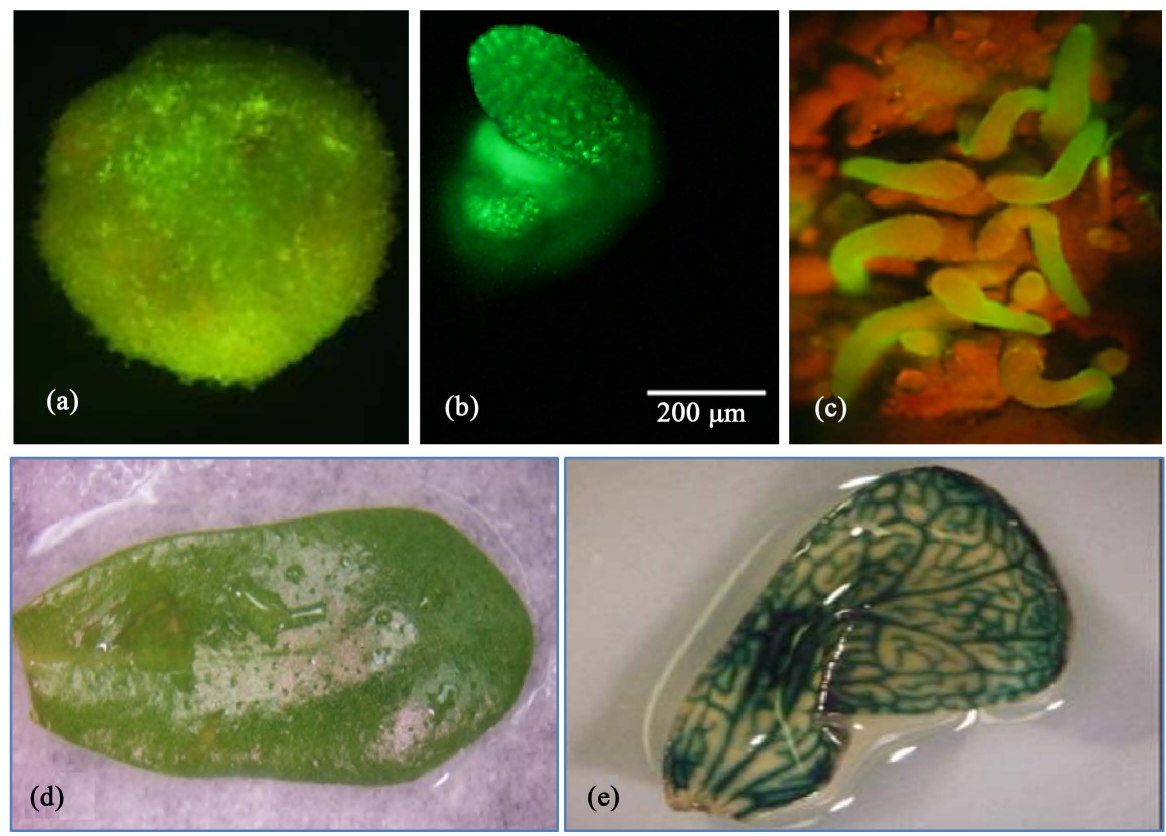

Figure 3. EGFP observation. (a) Transformed tTCL stem explant exhibiting GFP expression five days after co-cultivation; (b) Transgenic, GFP positive shoot bud induction on a tTCL stem explant 10 days after co-cultivation; (c) Adventitious rooting on tTCL stem explant 21 days after co-cultivation. Histochemical GUS Assay observation; (d) Normal leaf serves as control for GFP and GUS activity both; (e) Results of histochemical staining process in leaf. 


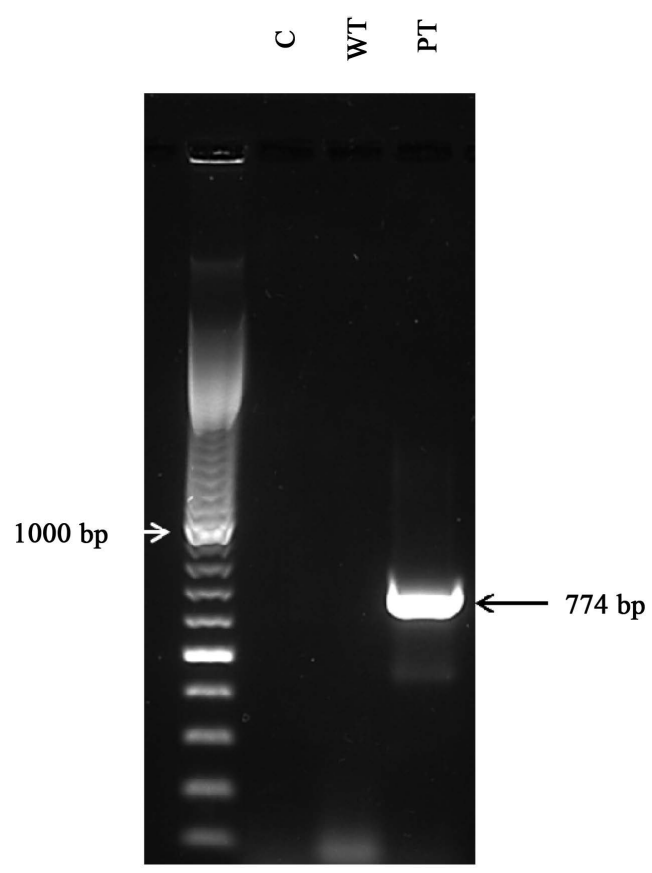

Figure 4. PCR studies on wild type and putative transgenic plant. The RT-PCR products were analyzed using $1.0 \%$ (w/v) agarose. M: 100 bp DNA step ladder (Promega), C: Control with No cDNA in the reaction, WT: Wild type plant, PT: Putative transgenic. Arrow indicates single amplified band for egfp gene.

Table 2. Total polyphenol content and TEAC assay of fresh and dried whole plants of Bacopa monnieri.

\begin{tabular}{cccc}
\hline Plant & Parts Used & TPP Content $^{*}(\mu \mathrm{g} / \mathrm{g} \mathrm{GAE})$ & TEAC $^{*}(\mu \mathrm{mol} / \mathrm{g})$ \\
\hline B. monnieri & Whole plant (Fresh) & $811.93 \pm 7.98^{\mathrm{a}}$ & $1918.25 \pm 173.12^{\mathrm{b}}$ \\
B. monnieri & Whole plant (Dried) & $814.37 \pm 17.64^{\mathrm{a}}$ & $3163.14 \pm 403.25^{\mathrm{a}}$ \\
R. officinalis & Whole plant (Fresh) & $249.99 \pm 11.01^{\mathrm{b}}$ & $1344.11 \pm 4.79^{\mathrm{a}}$ \\
R. officinalis & Whole plant (Dried) & $295.93 \pm 21.37^{\mathrm{b}}$ & $2092.06 \pm 21.37^{\mathrm{a}}$ \\
B. monnieri & Whole plant (Fresh) & $811.93 \pm 7.98^{\mathrm{a}}$ & $1918.25 \pm 173.12^{\mathrm{b}}$ \\
\hline
\end{tabular}

*Values given are means and \pm SE of four replicates. Means having different superscripts are significantly different from each other as per the Tukey’s HSD test $(p<0.05)$.

\section{Discussion}

Bacopa extracts have been extensively used in Indian Ayurvedic medicinal system for a number of human disorders including inflammation, pain, epilepsy, ulcer, and most importantly, for improving cognitive and other brain functions [8] [48] [49]. Mechanisms of cognitive and brain enhancement include its anti-oxidative activities [50] as well as modulation of the cholinergic system [51] [52]. Moreover, upregulation of neuronal and glial plasticity [53] and beta-amyloid scavenging activities [6] have also been reported. Among various pre-clinical reports for biological activities, the memory, attention or cognitive enhancing effect of Bacopa extracts have been confirmed by several double-blinded, placebo-controlled human clinical studies (reviewed by Pase et al. [49]). An ongoing randomized clinical trial to study the effect of Bacopa extract CDR1 08 on Attention Deficit Hyperactivity Disorder (ADHD) in children and adolescents has been reported [54], results of which are awaited.

The goal of this study was to develop and optimize protocols for in vitro adventitious shoot induction for $B$. monnieri using tTCL explants to raise commercially acceptable plant production with equal or better biological activity. This research is further optimization of our findings that were reported earlier [16]. We focused on optimizing the use of explant, choice of cytokinin and medium condition to develop a rapid multiplication system. 
It is interesting to note that tTCL explants need only two weeks on shoot induction medium in this protocol and elongate well within three weeks on liquid culture. There are no prior studies reporting multiple shoot induction using tTCL culture method for B. monnieri explants, or evaluating the effects of meta-Topolin (m-Topolin). However, high number of shoot induction in MS medium supplemented with $1.1 \mu \mathrm{M}$ BAP + $0.2 \mu \mathrm{M}$ IAA, resulting in 110 shoots from a single normal leaf explants was reported [13]. We have previously reported that increasing concentrations of BAP $(0.1,0.5$, and $1.0 \mathrm{mg} / \mathrm{L})$ had a positive effect on the number of shoots produced inducing 13,13, and 6 shoots respectively [12]. These differences could be due to the use of different genotype in the experiment. In vitro mass multiplication of B. monnieri using MS medium supplemented with $1.0 \mu \mathrm{M}$ of BAP was the best medium producing 41 shoots on a normal leaf explant [9]. Current study also supports the superiority of MS medium for shoot bud induction and elongation. Earlier report on organogenesis from normal Bacopa explants using leaves and internodes on different concentrations of BAP and 2,4-D showed that 0.5 $\mathrm{mg} / \mathrm{L}$ BAP and $0.5 \mathrm{mg} / \mathrm{L}$ 2,4-D produced highest number of shoots [16]. Cytokinin such as BAP in concentration of $6 \mu \mathrm{M}$ has shown to have high frequency of shoot bud regeneration from leaf explants [39]. Previous reports show that adventitious shoots can be regenerated from internodes using various concentrations of BAP and NAA [35]. In this study, meta-Topolin proved as an effective cytokinin, though not the best one (Figure 2). In case of S. barbata, and S. racemosa at the 14 and 21 day incubation periods meta-Topolin proved as the most effective cytokinin. Utilization of the $\operatorname{LLR}^{\circledR}$ system over semi-solid medium can decrease the cost of production since agar is not used in the medium (Figures $1(\mathbf{h})$-(j)), as well as the amount of time for roots to be successfully induced. Using this method, in vitro generated plantlet's transition for acclimatization is more efficient as all excess medium-derived nutrients and sucrose can be rinsed off with running tap water more effectively than with semi-solid medium.

We have earlier reported the success of micropropagating transverse versus longitudinal sections of $B$. monnieri [16]. However, these sections were not small enough to qualify as "thin cell layers". The mean length and width of a Bacopa leaf is $8.61 \mathrm{~mm} \times 27.00 \mathrm{~mm}$. One will be able to generate over thirty tTCL leaf explants from a single leaf, and utilizing the media preparation found in this study will be able to produce up to 59 plantlets per tTCL. In an optimized protocol, more than 1829 plantlets can be produced in one cycle from one leaf, which is far more than previous reports. When compared to previous studies using normal sized explants, the high number of shoots induced on such a thin layer of cells from the leaf and stem Bacopa explants, supersedes total shoots induced from one leaf or one internode explant [9] [13]. Given this research is focused on the optimization of multiple shoot induction, we completely omitted the use of a low level of auxin in the shoot induction medium as it resulted in rooting. The utilization of the LLR ${ }^{\circledR}$ system over semi-solid medium during elongation phase seems to have positive effects in that the omission of agar results in decreasing the cost of production, early root initiation, and plants are agar free for hardening process, bringing down the mortality rate. As there was no hyperhydricity case observed, scaled up liquid culture system can be an ideal technology for Bacopa mass production. As there is no need to orient explants in specific manner, and hood time taken by culturist is decreased resulting in higher productivity.

The transformation frequency utilizing leaf and stem tTCL explants correlates with past studies suggesting it to be a viable option [42] [55]. To study semi-quantitative analysis of the transgene at mRNA level, RT-PCR is a reliable technique. Leaf and stem tTCL explants both were suitable for transformation.

High TPP and TEAC values correlate with previously reported pre-clinical studies showing that this medicinal herb is effective in combating oxidative stress [50] [56]. A preliminary study on the antioxidant potential and total polyphenol content of this plant was also carried out during this research. As per recent studies that have evaluated the benefits of phenols and antioxidants against oxygen radicals and non-free radical species that cause oxidative stress, it is necessary to quantify the total polyphenol content (TPP) and antioxidant potential of the B. monnieri species [57]. Volluri et al. (2011) [58] reported $27.76 \pm 1.87 \mathrm{mg} / \mathrm{gm}$ GAE and Prasad et al. (2012) [59] reported $58 \mathrm{mg} / \mathrm{g}$ GAE TPP for B. monnieri. Solvents do affect the total phenolic content and antioxidant potential as the highest TPP, DPPH radical scavenging activity, and superoxide anion radical scavenging activities were reported with methanolic extracts as compared to hexane, petroleum ether, and water [60]. Previous studies report the TPP of B. monnieri whole plant in other conventional solvents, hexane, petroleum ether, water, and methanol, as 59.1, 88.0, 107.5, and $241.3 \mu \mathrm{g}$ GAE/g respectively [60]. Only methanolic extracts were measured in this study. The means of TPP for the fresh and dried greenhouse B. monnieri were $811.93 \pm 7.98$ and $814.37 \pm 17.64 \mathrm{mg} / \mathrm{g}$ GAE (Table 1). These numbers are the highest for fresh and dried TPC reported so far for $B$. monnieri. This study reports much higher GAE and TEAC values than prior studies [56] 
[59]. It can be concluded from this study, that the protocol utilized for in vitro micropropagation of $B$. monnieri is at this point a better choice in terms of economics and product turnover. The antioxidant protocol is especially useful in setting the baseline for future studies.

\section{Acknowledgements}

LAC and CLJ thank for Graduate Research Assistantship provided through "Strengthening the Minority Serving Institutions Project” (FVSU Project \# 331079, Dr. Nirmal Joshee, PD/PI) entitled "Advancing Graduate Education in the STEM Disciplines for the Underserved African American and Low Income American Population" funded by the United States Department of Education.

\section{References}

[1] Mukherjee, D.G. and Dey, C.D. (1966) Clinical Trial on Brahmi. International Journal of Experimental Medical Sciences, 10, 5-11.

[2] Escandon, A.S. (2006) A New Variety of Bacopa monnieri Obtained by in Vitro Polyploidization. Electronic Journal of Biotechnology, 9, 181-186. http://dx.doi.org/10.2225/vol9-issue3-fulltext-8

[3] Soundararajan, T. and Karrunakaran, C.M. (2011) Micropropagation of Bacopa monnieri through Protoplast. Asian Journal of Biotechnology, 3, 135-152. http://dx.doi.org/10.3923/ajbkr.2011.135.152

[4] Bose, K.C. and Bose, N.K. (1931) Observation on the Action and Uses of Herpestismonneri (Scrophulariaceae). Journal of Indian Medical Association, 1, 60-64.

[5] Fransworth, N.R. (1966) Biological and Phytochemical Screening of Plants. Journal of Pharmaceutical Sciences, 55, 225-276. http://dx.doi.org/10.1002/jps.2600550302

[6] Ramesh, M., Marx, R., Mathan, G. and Pandian, S.K. (2007) Effect of Bavistin on in Vitro Plant Conversion from Encapsulated Uninodalmicrocuttings of Micropropagated Bacopa monnieri (L.) - An Ayurvedic Herb. Journal of Environmental Biology, 30, 441-444.

[7] Kulkarni, R., Girish, K.J. and Kumar, A. (2012). Nootropic Herbs (Medhya Rasayana) in Ayurveda: An Update. Pharmacognosy Reviews, 6, 147-153. http://dx.doi.org/10.4103/0973-7847.99949

[8] Russo, A. and Borrelli, F. (2005) Bacopa monniera, a Reputed Nootropic Plant: An Overview. Phytomedicine, 4, 305318. http://dx.doi.org/10.1016/j.phymed.2003.12.008

[9] Sharma, S., Kamal, B., Rathi, N., Chauhan, S., Jadon, V., Vats, N., Gehlot, A. and Arya, S. (2010) In Vitro Rapid and Mass Multiplication of Highly Valuable Medicinal Plant Bacopa monnieri (L.) Wettst. African Journal of Biotechnology, 9, 8318-8322.

[10] Tiwari, V., Tiwari, K.N. and Singh, B.D. (2000) Suitability of Liquid Cultures for in Vitro Multiplication of Bacopa monnieri (L.) Wettst. Phytomorphology, 50, 337-342.

[11] Tascan, A., Adelberg, J., Tascan, M., Rimando, A., Joshee, N. and Yadav, A.K. (2010) Hyperhydricity and Flavonoid Content of Scutellaria Species in Vitro on Polyester-Supported Liquid Culture Systems. HortScience, 45, 1723-1728.

[12] Tiwari, V., Tiwari, K.N. and Singh, B.D. (2001) Comparative Studies of Cytokinins on in Vitro Propagation of Bacopa monniera. Plant Cell, Tissue and Organ Culture, 30, 9-16. http://dx.doi.org/10.1023/A:1010652006417

[13] Chaplot, B.B., Ashok, D.M. and Yogesh, J.T. (2005) Bacopa monnieri (L.) Pennell; A Rapid, Efficient and Cost Effective Micropropagation. Plant Tissue Culture and Biotechnology, 15, 167-175.

[14] Sharma, N., Satsangi, R., Pandey, R., Devi, S. and Vimala, S. (2007). In Vitro Clonal Propagation and Medium Term Conservation of Brahmi (Bacopa monnieri). Journal of Plant Biochemistry and Biotechnology, 16, 139-142. http://dx.doi.org/10.1007/BF03321990

[15] Vijayakumar, M.R. (2010) In Vitro Propagation of Bacopa monnieri L.-A Multipurpose Medicinal Plant. Indian Journal of Science and Technology, 3, 781-786.

[16] Joshee, N., Harris, D. and Yadav, A.K. (2007) Influence of Explant Selection and Culture Conditions on Organogenesis and Germplasm Conservation of Bacopa monnieri (L.) Wettst. Acta Horticulturae, 756, 163-170. http://dx.doi.org/10.17660/actahortic.2007.756.13

[17] Showkat, P., Zaidi, Y., Asghar, S. and Jamaluddin, S. (2010) In Vitro Propagation and Callus Formation of Bacopa monnieri (L.) Penn. Plant Tissue Culture and Biotechnology, 20, 119-125.

[18] Tanveer, A., Khan, M. and Shah, F. (2010) In Vitro Micropropagation of Brahmi-Bacopa monnieri (L.) Pennel-A Step for Conservation. Nanobiotechnica Universale, 1, 139-150.

[19] Werbrouck, S.P., Strnad, M., Van Onckelen, H.A. and Debergh, P.C. (1996) Meta-Topolin, an Alternative to Benzyla- 
denine in Tissue Culture? Physiologia Plantum, 98, 291-297. http://dx.doi.org/10.1034/j.1399-3054.1996.980210.x

[20] Gomez-Leyva, J.F., Martinez-Acosta, I.G., Lopez Muraira, H., Silos, E., Ramirez-Cervantes, F. and Andrade-Gonzalez, I. (2008) Multiple Shoot Regeneration of Roselle (Hibiscus sabdariffa L.) from a Shoot Apex Culture System. International Journal of Botany, 326-330.

[21] Chuenboonngarm, N., Charoonsote, S. and Bhamarapravati, S. (2001) Effect of BA and 2iP on Shoot Proliferation and Somaclonal Variation of Gardenia jasminoides Ellis in Vitro Culture. ScienceAsia, 27, 137-141. http://dx.doi.org/10.2306/scienceasia1513-1874.2001.27.137

[22] Nhut, D.T., Le, B.V., Teixeira da Silva, J.A., Jeanneau, S.M., Do My, N.T., Vidal, J. and Tran Thanh Van, K. (2003) Genetic Transformation Using Thin Cell Layer Method. In: Nhut, D.T., Van Le, B., Tran Thanh Van, K. and Thorpe, T., Eds., Thin Cell Layer Culture System: Regeneration and Transformation Applications, Kluwer Academic Publishers, Netherlands, 495-512. http://dx.doi.org/10.1007/978-94-017-3522-3_14

[23] Tran Than Van, M. (1973) In Vitro Control of de Novo Flower, Bud, Root and Callus Differentiation from Excised Epidermal Tissues. Nature, 246, 44-45. http://dx.doi.org/10.1038/246044a0

[24] Teixeira da Silva, J.A. and Fukai, S. (2002) Change in Transgene Expression Following Transformation of Chrysanthemum by Four Gene Introdution Methods. Propagation of Ornamental Plants, 2, 28-37.

[25] Teixeira da Silva, J.A. and Fukai, S. (2003) Increasing Transient and Subsequent Stable Transgene Expression in Chrysanthemum Dendranthem x grandiflora Ramat. Kitamura Following Optimization of Particle Bombardment and AgroInfection Parameters. Plant Biotechnology, 19, 229-240. http://dx.doi.org/10.5511/plantbiotechnology.19.229

[26] Teixeira da Silva, J.A. (2003) Tissue Culture and Cryopreservation of Chrysanthemum: A Review. Biotechnological Advance, 21,715-716. http://dx.doi.org/10.1016/S0734-9750(03)00117-4

[27] Tran Than Van, M., Tan Nhut, D., Teixeira Da Silva, J.A. and Aswath, C.R. (2003) The Importance of the Explant on Regeneration in Thin Cell Layer Technology. In Vitro Cellular and Development Biololgy_Plant, 39, 266-276. http://dx.doi.org/10.1079/IVP2002408

[28] Singh, S.K., Rai, M.K. and Sahoo, L. (2012) An Improver and Efficient Micropropagation of Eclipta alba through Transverse Thin Cell Layer Culture and Assessment of Clonal Fidelity Using RAPD Analysis. Industrial Crops and Products, 37, 328-333. http://dx.doi.org/10.1016/j.indcrop.2011.12.005

[29] Marsh, Z., Yang, T., Nopo-Olazabal, L., Wu, S., Ingle, T., Joshee, N. and Medina-Bolivar, F. (2014) Effect of Light, Methyl Jasmonate and Cyclodextrin on Production of Polyphenolic Compounds in Hairy Root Cultures of Scutellaria lateriflora. Phytochemistry, 107, 50-60. http://dx.doi.org/10.1016/j.phytochem.2014.08.020

[30] Wilson, S.A. and Roberts, S.C. (2014) Metabolic Engineering Approaches for Production of Biochemicals in Food and Medicinal Plants. Current Opinion in Biotechnology, 26, 174-182. http://dx.doi.org/10.1016/j.copbio.2014.01.006

[31] Murashige, T. and Skoog, F. (1962) A Revised Medium for Rapid Growth and Bioassays with Tobacco Tissue Cultures. Physiologia Plantarum, 15, 473-497. http://dx.doi.org/10.1111/j.1399-3054.1962.tb08052.x

[32] Brearley, T.A., Vaidya, B.N. and Joshee, N. (2014) Cytokinin, Carbon Source and Acclimatization Requirements for in Vitro Propagation of Scutellaria barbata D. Don and Scutellaria racemosa Pers. American Journal of Plant Sciences, 5, 3662-3672. http://dx.doi.org/10.4236/ajps.2014.524382

[33] Dhekney, S.A., Li, Z.T. and Gray, D.J. (2011) Agrobacterium-Mediated Transformation and Regeneration of Transgenic Tobacco Plants. In: Trigiano, R. and Gray, D., Eds., Plant Cell Culture, Development and Biotechnology, 3rd Edition, Taylor and Francis, Boca Raton, 467-472.

[34] Jefferson, R.A., Kavanagh, T.A. and Bevan, M.W. (1987) Gus Fusions: ß-Glucuronidase as a Sensitive and Versatile Gene Marker in Higher Plants. The EMBO Journal, 6, 3901-3907.

[35] Vaidya, B.N., Brearley, T.A. and Joshee, N. (2013) Antioxidant Capacity of Fresh and Dry Leaf Extracts of Sixteen Scutellaria Species. Journal of Medicinally Active Plant, 2, 42-49.

[36] Lowry, O.H., Rosebrough, N.J., Farr, A.L. and Randall, R.J. (1951) Protein Measurement with the Folin Phenol Reagent. Journal of Biological Chemistry, 193, 265-275.

[37] Re, R., Pellegrini, N., Proteggente, A., Pannala, A., Yang C. and Rice-Evans, M. (1999) Antioxidant Activity Applying an Improved ABTS Radical Cation Decolorization Assay. Free Radical Biology and Medicine, 26, 1231-1237. http://dx.doi.org/10.1016/S0891-5849(98)00315-3

[38] Yi, W. and Wetzstein, H. (2010) Biochemical, Biological and Histological Evaluation of Some Culinary and Medicinal Herbs Grown under Greenhouse and Field Conditions. Journal of Science, Food and Agriculture, 90, 1063-1070. http://dx.doi.org/10.1002/jsfa.3921

[39] Gamborg, O., Miller, R. and Ojima, K. (1968) Nutrient Requirement Suspensions Cultures of Soybean Root Cells. Experimental Cell Research, 50, 151-158. http://dx.doi.org/10.1016/0014-4827(68)90403-5

[40] Joshi, A., Pathak, G., Sharma, A.R. and Singh, S. (2010) High Frequency of Shoot Regeneration on Leaf Explants of 
Bacopa monnieri. Environmental and Experimental Biology, 8, 81-84.

[41] Karatas, M., Aasim, M., Dogan, M. and Khawar, K.M. (2013) Adventitious Shoot Regeneration of the Medicinal Aquatic Plant Water Hyssop (Bacopa monnieri L. Pennell.) Using Different Internodes. Archives of Biological Sciences, 65, 297-303. http://dx.doi.org/10.2298/ABS1301297K

[42] Nisha, K.K., Seetha, K., Rajmohan, K. and Purushothama, M.G. (2003) Agrobacterium tumefaciens-Mediated Transformation of Brahmi (Bacopa monniera (L.) Wettst.), a Popular Medicinal Herb of India. Current Science, 85, 85-89.

[43] Ramesh, M., Karthikeyan, A., Vijayakumar, K., Joe Virgin Largia, M. and Pandian, S.K. (2011) Agrobacterium-Mediated Transformation of Pharmacautically Important Indian Medicinal Herb Bacopa monnieri (L.) Journal of Medicinal Plants Research, 5, 2316-2321.

[44] Majumdar, S., Garai, S. and Jha, S. (2011) Genetic Transformation of Bacopa monnieri by Wild Type Strains of Agrobacterium rhizogenes Stimulates Production of Bacopa saponins in Transformed Calli and Plants. Plant Cell Report, 30, 941-954. http://dx.doi.org/10.1007/s00299-011-1035-9

[45] Aggarwal, D., Jaiswal, N., Kumar, A. and Reddy, M.S. (2013) Factors Affecting Genetic Transformation and Shoot Organogenesis of Bacopa monnieri (L.) Wettst. Journal of Plant Biochemistry and Biotechnology, 22, 382-391. http://dx.doi.org/10.1007/s13562-012-0166-6

[46] Yadav, S., Sharma, P., Srivastava, A., Desai, P. and Shrivastava, N. (2014) Strain Specific Agrobacterium-Mediated Genetic Transformation of Bacopa monnieri. Journal of Genetic Engineering and Biotechnology, 12, 89-94. http://dx.doi.org/10.1016/j.jgeb.2014.11.003

[47] Kumari, U., Vishwakarma, R., Gupta, N., Ruby, Shirgurkar, M. and Khan, B. (2015) Efficient Shoots Regeneration and Genetic Transformation of Bacopa monniera. Physiology and Molecular Biology of Plants, 21, 261-267. http://dx.doi.org/10.1007/s12298-015-0290-6

[48] Stough, C., Singh, H. and Zangara, A. (2015) Mechanisms, Efficacy and Safety of Bacopa monnieri (Brahmi) for Cognitive and Brain Enhancement (Editorial). Evidence-Based Complementary and Alternative Medicine, 2015, Article ID: 717605. http://dx.doi.org/10.1155/2015/717605

[49] Pase, M.P., Kean, J., Sarris, J., Neale, C., Scholey, A.B. and Stough, C. (2012) The Cognitive-Enhancing Effects of Bacopa monnieri: A Systematic Review of Randomized, Controlled Human Clinical Trials. Journal of Alternative and Complementary Medicine, 18, 647-652. http://dx.doi.org/10.1089/acm.2011.0367

[50] Bhattacharya, S.K., Bhattacharya, A., Kumar, A. and Ghosal, S. (2000) Antioxidant Activity of Bacopa monniera in Rat Frontal Cortex, Striatum and Hippocampus. Phytotherapy Research, 14, 174-179. http://dx.doi.org/10.1002/(SICI)1099-1573(200005)14:3<174::AID-PTR624>3.0.CO;2-O

[51] Bhattacharya, S.K., Kumar, A. and Ghosal, S. (1999) Effect of Bacopa monniera on Animal Models of Alzheimer's Disease and Perturbed Central Cholinergic Markers of Cognition in Rats. In: Siva Sankar, D.V., Ed., Molecular Aspects of Asian Medicines, PJD Publications, New York.

[52] Uabundit, N., Wattanathorn, J., Mucimapura, S. and Ingkaninan, K. (2010) Cognitive Enhancement and Neuroprotective Effects of Bacopa monnieri in Alzheimer’s Disease Model. Journal of Ethnopharmacology, 127, $26-31$. http://dx.doi.org/10.1016/j.jep.2009.09.056

[53] Konar A., Gautam A. and Thakur M.K. (2015) Bacopa monniera (CDRI-08) Upregulates the Expression of Neuronal and Glial Plasticity Markers in the Brain of Scopolamine Induced Amnesic Mice. Evidence-Based Complementary and Alternative Medicine, 2015, Article ID: 837012. http://dx.doi.org/10.1155/2015/837012

[54] Kean, J., Kaufman, J., Lomas, J., Goh, A., White, D., Scholey, A.B., Singh, H., Sarris, J., Zangara, A. and Stough, C. (2015) A Randomized Controlled Trial Investigating the Effects of a Special Extract of Bacopa monnieri (CDRI 08) on Hyperactivity and Inattention in Male Children and Adolescents: BACHI Study Protocol (ANZCTRN12612000827831). Nutrients, 7, 9931-9945. http://dx.doi.org/10.3390/nu7125507

[55] Mahender, A., Mallesham, B., Srinivas, K., Kumar, G.K., Rajesh, Y., Zhang, P., Rao, K.V. and Sadanandam, A. (2012) A Rapid and Efficient Method for in Vitro Shoot Organogenesis and Production of Transgenic Bacopa monnieri L. Mediated by Agrobacterium tumefaciens. In Vitro Cellular and Developmental Biology_Plant, 48, 153-159. http://dx.doi.org/10.1007/s11627-011-9421-0

[56] Ghosh, T., Maity, T.K., Bose, A., Das, G.K. and Das, M. (2007) In Vitro Antioxidant and Hepatoprotective Activity of Ethanolic Extract of Bacopa monnieri Linn. Aerial Parts. Iranian Journal of Pharmacology and Therapeutics, 6, $77-$ 85.

[57] Rohman, A., Riyanto, S., Yuniarti, N., Saputra, W.R., Utami, R. and Mulatsih, W. (2010) Antioxidant Activity, Total Phenolic and Total Flavonoid of Extracts and Fractions of Red Fruit (Pandanus conoideus Lam) International Food Research Journal, 17, 97-106.

[58] Volluri, S.S., Bammidi, S.R., Chippada, S.C. and Vagalapati, M. (2011) In Vitro Antioxidant Activity and Estimation of Total Phenolic Content in Methanolic Extract of Bacopa monniera. Rasayan Journal of Chemistry, 4, 381-386. 
[59] Prasad, M.S., Manoranjan, S., Venkateshwarlu, G., Madhu, C.H., Sambasivarao, A. and Patro, S. (2012) Estimation of Total Phenolic Content and in Vitro Antioxidant Activity of Bacopa monnieri. International Journal of Phytotherapy Research, 2, 21-25.

[60] Kumar, G.P. and Khanum, F. (2012) Neuroprotective Potential of Phytochemicals. Pharmacognosy Review, 12, 81-90. http://dx.doi.org/10.4103/0973-7847.99898 